\title{
On assessment of processing variables in vertical centrifugal casting technique
}

\author{
G. Chirita ${ }^{1}$, I. Stefanescu ${ }^{2}$, J. Barbosa ${ }^{2}$, H. Puga $^{1}$, D. Soares ${ }^{1}$ and F. S. Silva*1
}

The aim of the present study is to investigate the influence of the vertical centrifugal casting technique over mechanical and metallurgical properties of a hypereutectic Al-18Si alloy. Due to the inherent vibration of the centrifugal casting technique, and in order to study and understand the individual effects of the equipment vibration and the centrifugal force itself (pressure or fluid dynamics), as well as the combined effect of both, three different tests were performed: gravity casting, gravity casting with vibration and centrifugal casting. It was concluded that the metallurgical and mechanical properties of castings obtained by the centrifugal casting process depend on the combined effect of the centrifugal pressure and/or fluid dynamics and on the inherent vibration of the technique itself. Correlations between the different casting techniques and obtained mechanical and metallurgical properties are presented.

Keywords: Centrifugal casting, Vibration, Fluid dynamics, Pressure

\section{Introduction}

An excellent combination of castability, mechanical properties, good corrosion resistance and weldability, makes cast aluminium alloys one of the most important materials used in aerospace and automotive industries.

Furthermore, the relatively low coefficient of thermal expansion, mainly in hypereutectic Al-Si alloys, and excellent fluidity, make this alloy family as a candidate material for a large number of automotive applications such as pistons, cylinder blocks and heads and even liners. $^{1-4}$

The main drawback of cast Al-Si alloys is perhaps that under the conventional solidification conditions the Si phase often exhibits a coarse microstructure that leads to poor mechanical properties and fracture behaviour, which are strongly dependent on secondary dendrite arm spacing (SDAS), on volume fraction and morphology of the eutectic silicon phase and on the presence of Fe rich intermetallics. Thus, not only the chemical composition but, not less important, the microstructure morphology, has a strong influence on mechanical and also on fatigue properties of Al-Si cast alloys. ${ }^{5,6}$

Nevertheless, recent results have demonstrated that rapid solidification processes and mechanically based microstructure refinement may substantially modify the morphology of the $\mathrm{Si}$ phase when compared to that found in conventionally processed materials, ${ }^{7,8}$ namely those where the lamellar to fibrous $\mathrm{Si}$ modification is achieved by strontium, sodium or antimony addition. ${ }^{9-12}$ As a simplistic approach, it can be considered that the

${ }^{1}$ Mechanical Engineering Department, School of Engineering, Minho University, Campus de Azurem, Guimaraes, 4800-058, Portugal

${ }^{2}$ Faculty of Mechanical Engineering, Dunarea de Jos University Galati, Romania

*Corresponding author, email fsamuel@dem.uminho.pt use of casting processes involving die casting technologies (or permanent moulds in general) is probably the best way to improve the mechanical properties of aluminiumsilicon based alloys. ${ }^{13-17}$

\section{Vertical centrifugal casting}

Among the different aluminium casting techniques centrifugal casting is an example of a casting technology used with success to obtain improved mechanical results. Although in some studies the materials used are aluminium matrix composites where the improvement of mechanical properties is attributed to the reinforcement, it is documented that the centrifugal casting process can give an important contribution to improve the mechanical properties of aluminium alloys even if it is applied to alloys without reinforcement. ${ }^{2,13,18,19}$

Traditionally the centrifugal casting process has been mainly used for obtaining cylindrical parts. There are essentially two basic types of centrifugal casting machines: the horizontal types, where the die rotates around a horizontal axis, and the vertical type, where the die rotates around a vertical axis. Horizontal centrifugal casting machines are generally used to make pipes, tubes, bushings, cylinder sleeves (liners), and cylindrical or tubular castings that are simple in shape. The range of applications of vertical centrifugal casting machines is considerably wider: gear blanks, pulley sheaves, wheels, impellers, electric motor rotors, valve bodies, plugs, yokes, brackets. Castings that are not cylindrical or even symmetrical, can be obtained by vertical centrifugal casting. Centrifugally cast parts have a high degree of metallurgical cleanliness and homogeneous microstructures, and they do not exhibit the anisotropy of mechanical properties evident in rolled/ welded or forged parts. Directional solidification provides for clean, dense castings with physical properties 
that are often superior to those of the static casting processes.

The effect of the vertical centrifugal process on castings can be due to one or more of the following three main features: centrifugal pressure; fluid dynamics; intrinsic vibration of the process. ${ }^{13}$ The effect of each of these variables may be responsible for the enhancement found in both mechanical and metallurgical properties of the castings. Although the beneficial effect of the centrifugal casting process is well accepted an explanation for the reasons of that occurrence are not fully explored yet. $^{2}$

Thus, in order to understand whether the centrifugal effect is due to the inherent vibration of the process or to the centrifugal pressure and fluid dynamics, three different tests were performed: gravity casting as a baseline process, gravity casting with vibration in order to simulate the additional effect of the inherent vibration of the vertical centrifugal process, and vertical centrifugal casting in order to evaluate all the full process variables, e.g. the effect of fluid dynamics, centrifugal pressure, and inherent vibration.

\section{Vibration effect}

It is documented that the application of mechanical vibration to the mould during solidification has an effect on the microstructure and consequently on mechanical properties of the casting. ${ }^{5,6}$ The lamellar spacing tends to reduce and silicon morphology becomes fibrous with the increase of the vibration amplitude as compared to gravity casting. However, exceeding a critical value of acceleration (relationship between frequency and displacement amplitude), the silicon tends to coarsen. ${ }^{6}$

Fragmented primary dendrites with higher arm thickness and reduced solidification time were obtained on Al-8Si with rectilinear vibration at 100 cycles min $^{-1}$ ( $\sim 2 \mathrm{~Hz}$ ). The same level of vibration was applied to Al$12 \mathrm{Si}$ and it was reported a reduction of the eutectic cell size from 5 to $1.6 \mathrm{~mm}$ and a coarsening tendency of the eutectic $\mathrm{Si}^{20}$ Metal vibration at a constant frequency of $100 \mathrm{~Hz}$ and amplitudes from 18 to $199 \mu \mathrm{m}$ was reported to increase the alloy elongation between 19 and $68 \%$ and a slight increase around $3 \%$ in the ultimate stress. ${ }^{6}$ The increase in elongation was correlated with the increase in the amount of eutectic composition compared to the non-vibrated case. ${ }^{6}$ Moreover, significant reduction in gas content was obtained with low frequency melt agitation in $\mathrm{Al}-20 \mathrm{Si}^{21}$ Nevertheless, in another study the volume fraction and size of pores increased in LM25 (Al-7Si) and LM6 (Al-12Si) alloys with increasing frequencies between 15 and $41.7 \mathrm{~Hz}$ and amplitudes between 0.125 and $0.5 \mathrm{~mm}^{22}$

\section{Fluid dynamics}

The fluid dynamics of aluminum alloys has a direct influence not only on material castability, but also on the casting properties. Fluid dynamics is a complex parameter that is affected by the properties of the molten metal and mould, pouring conditions and solidification mechanisms. Fluid dynamics has an important role on casting properties due mainly to the influence on solidification sequence.

The fluid dynamics is expected to be very different under gravitational force (gravity casting), gravitational force and vibrating movement (vibrating gravity casting) and under centrifugal pressure + gravity pressure + inherent vibration (centrifugal casting). It is expected that the turbulence of the melt in the centrifugal process is much higher inside the mould. According to Ref. 23, the first melt reaching the wall surface of the mould (where the first germens of solidification appear) will came backwards to the inside part of the mould cavity increasing the number of solidification sites in the inner part of the casting and consequently promoting a quicker solidification and a refined microstructure, as compared to the gravity casting process. $^{13}$

\section{Centrifugal pressure}

During solidification the molten alloy is subjected to external forces that influence the solidification behaviour as, for example, gravitational force in gravity casting, lateral forces due to vibration movement in vibrating gravity casting and also the combined effect of vibration and centrifugal pressure in the case of centrifugal casting.

The centrifugal pressure applied on the melt during solidification can significantly decrease the percentage of porosity, increase the density, decrease the grain size of $\alpha$-Al, and modify the eutectic $\mathrm{Si}^{14,16,17}$

It is also important to highlight that the centrifugal pressure may have an influence on the positioning of the densest phases during solidification, which have tendency to move to the outer part of the casting due to the centrifugal force. ${ }^{15}$ Thus it is expected that in alloys where phases with different densities coexist the densest ones will concentrate on the outer part of the casting. This is what happens with most of composite particle reinforced materials obtained by centrifugal casting ${ }^{24}$ (also called functionally graded materials).

In this paper, the effect of both the inherent vibration of the centrifugal process as well as the centrifugal pressure and fluid dynamics on the mechanical properties of the castings will be evaluated.

\section{Experimental methods and materials}

The material used in every casting technique evaluated on this work was a commercial Al-18Si alloy.

The alloy was melted at $800^{\circ} \mathrm{C}$ and poured into a permanent mould preheated at $130^{\circ} \mathrm{C}$. A high frequency induction furnace (Titancast $700 \mathrm{mP}$ Vac, from Linn High Term, Germany), equipped with a vacuum melting and pouring chamber, was used for melting the alloy (see scheme in Fig. 1) A melting stock of $\sim 240 \mathrm{~g}$ was used in each experiment.

For the centrifugal casting experiments, the molten alloy was automatically poured into the mould cavity due to the off-centre position of the melting crucible in relation to the rotation axis of the chamber sustaining arm (Fig. 1a). In order to record the frequency and vibration amplitude of the vertical centrifugal casting process, accelerometers were attached in different directions to the centrifugal casting machine, during one experiment. The recorded frequency was $8 \mathrm{~Hz}$ and the amplitude was $0.5 \mathrm{~mm}$, essentially in just one direction.

For gravity and gravity with vibration casting experiments the same induction vacuum melting equipment was used for melting, but in these cases the melt was manually poured into the mould (Fig. $1 b$ and $c$ ). In the particular case of the vibrating casting experiments, the molten alloy was poured into a mould attached to a 


\section{Centrifugal}

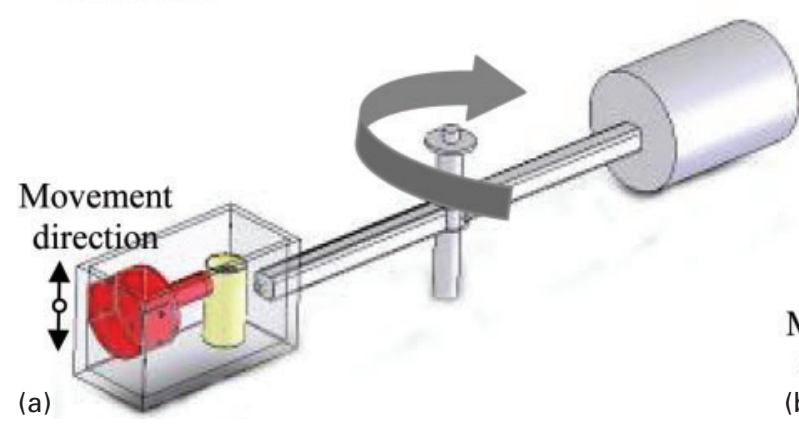

Gravity + Vibration

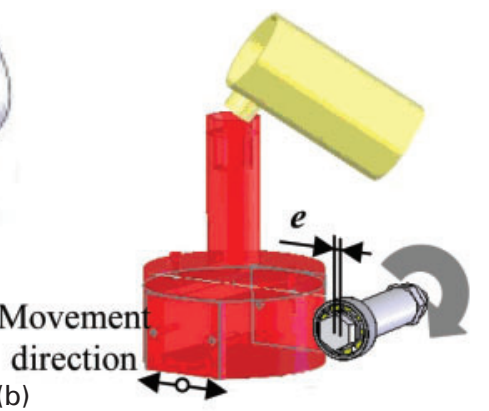

Gravity

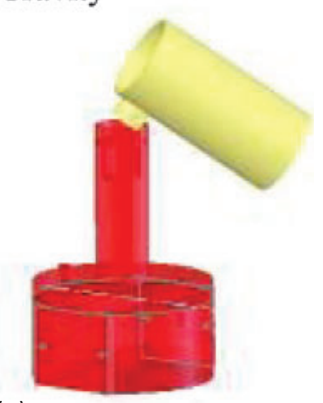

(c)

1 Schematic representation of a centrifugal casting, $b$ vibration gravity casting and $c$ gravity casting

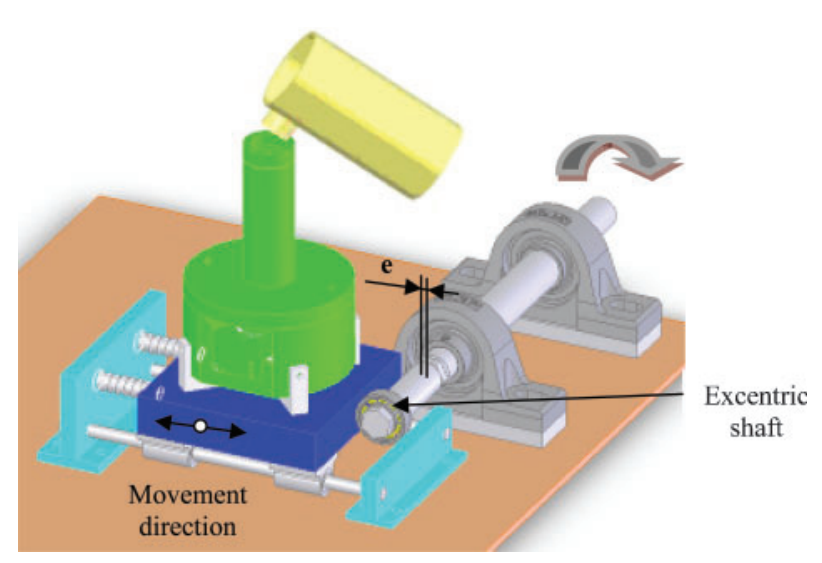

2 Gravity vibrating casting device

device that provided the mechanical vibration. In order to reproduce the vibration parameters of the centrifugal casting experiments a mechanical displacement with the same amplitude, $e$, and frequency measured on the centrifugal casting equipment was linearly applied by the action of a suitable designed eccentric shaft over a guided moving platform (Fig. 2).

The obtained castings were heat treated at $200^{\circ} \mathrm{C}$ for $8 \mathrm{~h}$.

Every sample obtained by centrifugal casting (Fig. 3a), gravity casting and vibrating gravity casting (Fig. $3 b$ ) were cut in three $3 \mathrm{~mm}$ thickness slices in order to compare the properties of the aluminium alloy not only between casting methods but also in different places of the samples. From Fig. 3 it is possible to observe that the obtained casting is rectangular $(90 \times 30 \times 30 \mathrm{~mm})$ and the place from where the specimens were cut.

To be able to make an analysis of the samples solidification behaviour two thermocouples (type K) were attached to the mould in order to acquire temperatures during pouring and solidification stages. Two holes were made in the wall of the mould in which thermocouples were inserted at a distance of $2 \mathrm{~mm}$ from the inside wall surface. The positions of the thermocouple are shown in Fig. 4.

A casting solidification simulation was performed using the commercial NovaFlow\&Solid finite differences simulation software.

Tensile tests were performed at room temperature in a Dartec tensile testing machine. After making the tensile tests the specimens were cut near the fracture surface, polished, and an optical measurement method was used for phase quantification. The microstructure examination was made on the middle part of each sample.

\section{Results}

In this section results of mechanical tests (rupture strength and rupture strain) and metallurgical examinations (phase quantification and eutectic silicon lamellas thickness) will be presented.

The mechanical testing results are shown in Figs. 5 and 6.

As a first remark, it can be assumed that the highest mechanical properties correspond to the centrifugally obtained samples and the lowest properties to the gravity poured ones. The difference in rupture strength is about $28 \%$ when compared to gravity castings with vibration and $42 \%$ when compared to gravity castings (Fig. 5). Regarding rupture strain these differences are higher - for example in position 1 it is about $280 \%$ higher when compared to gravity castings with vibration and about 300\% higher when compared to gravity castings (Fig. 6). As a final remark, it seems clear that the vibration effect improves the mechanical properties of gravity castings.

In what concerns to properties evolution between different locations of the cast samples, the tendencies of the rupture strength and rupture strain show an increase (a)

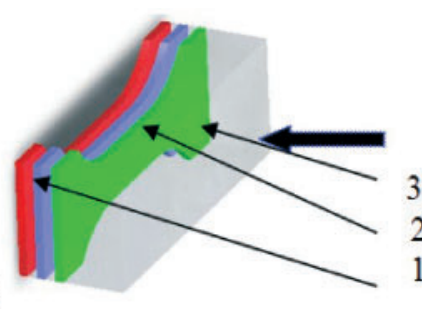

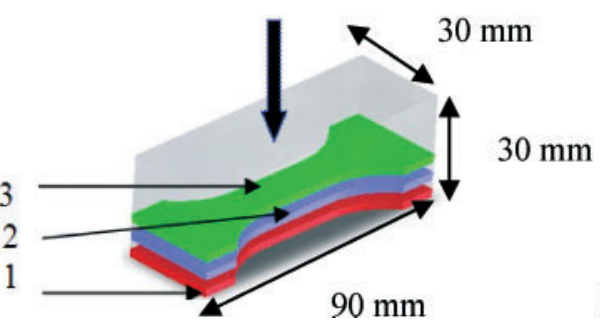

(b) 


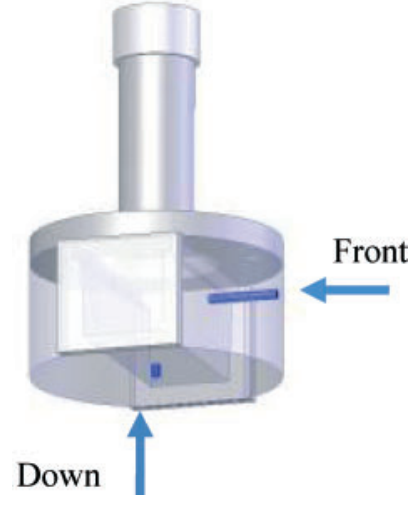

4 Temperature measurement positions in mould

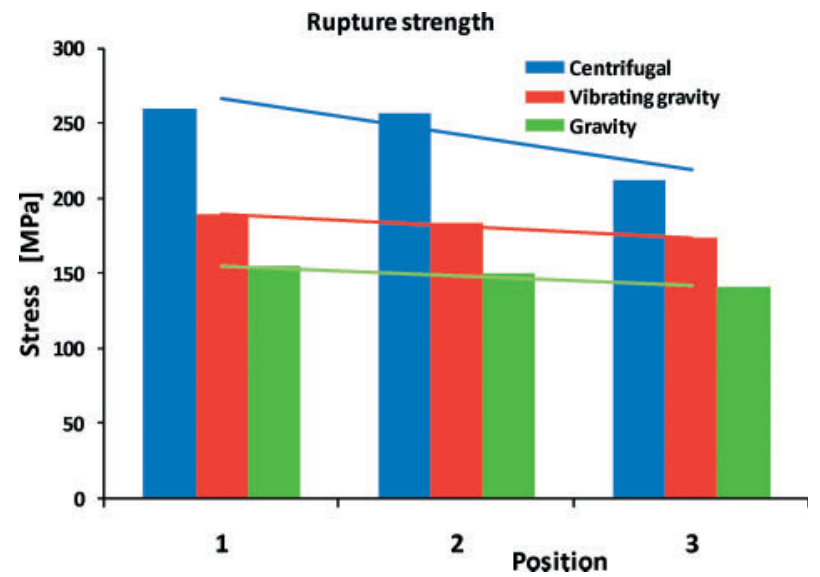

5 Rupture strength for three casting techniques: gravity; gravity with vibration $(8 \mathrm{~Hz})$; centrifugal casting

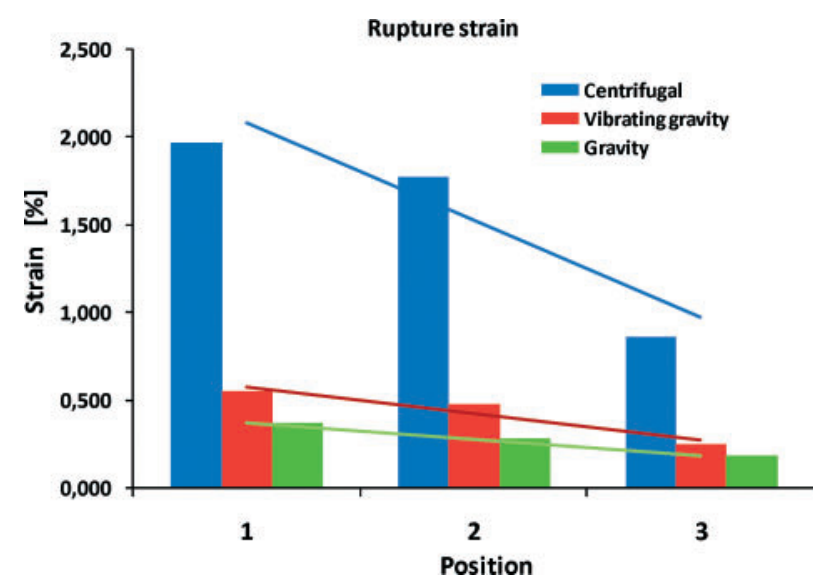

6 Rupture strain for three casting techniques: gravity; gravity with vibration $(8 \mathrm{~Hz})$; centrifugal casting

from position 3 (inside the casting) to position 1 (casting surface) for every casting technique. Furthermore, the difference between position 1 and position 3 (slope of the curve) is substantially higher in centrifugally casts samples (Figs. 5 and 6).

An example of the samples microstructure for the three different castings techniques are presented in Fig. 7. It is observed that the morphology of eutectic silicon was modified from a very dispersed coral-like form (gravity) to a finely but non-uniformly distributed

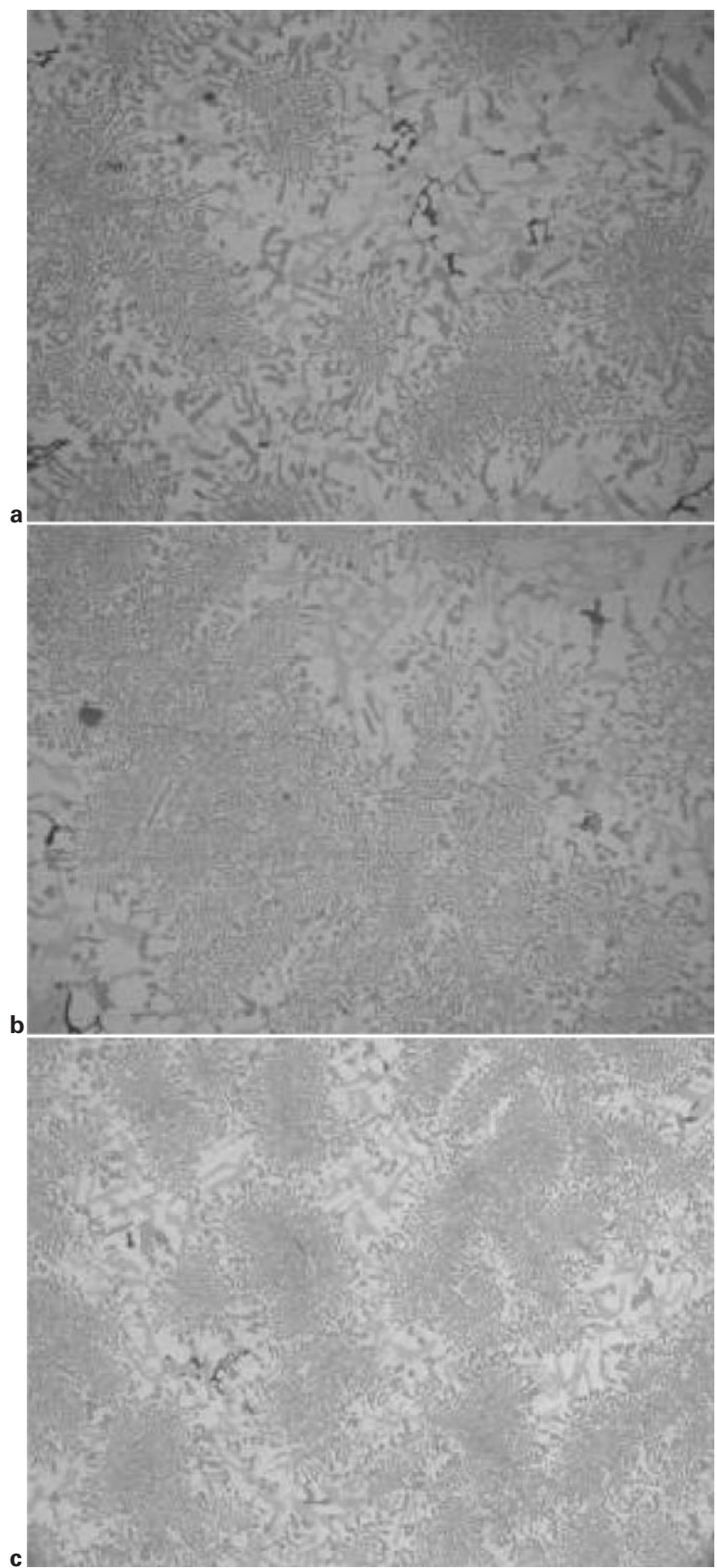

a gravity; $b$ gravity with vibration $(8 \mathrm{~Hz}) ; c$ centrifugal casting

7 Microstructures for three casting techniques $(500 \times)$

coral-like form (gravity with vibration) and to a more finely and uniformly coral-like eutectic form when centrifugal casting was used.

The volume fraction of $\alpha$-Al phase shows a decreasing tendency from position 3 to position 1 in all the studied cases (centrifugal, gravity and vibrated gravity casting) (Fig. 8); The eutectic's volume fraction has the opposite tendency, e.g. an increasing tendency from position 3 to position 1 in all the studied cases (Fig. 8). Comparing the casting techniques it can be verified that considering the gravity casting volume fraction as a comparison value the amount of eutectic volume fraction increases in about $14 \%$ for gravity cast samples with vibration and approximately $20 \%$ for centrifugally cast samples, in all 


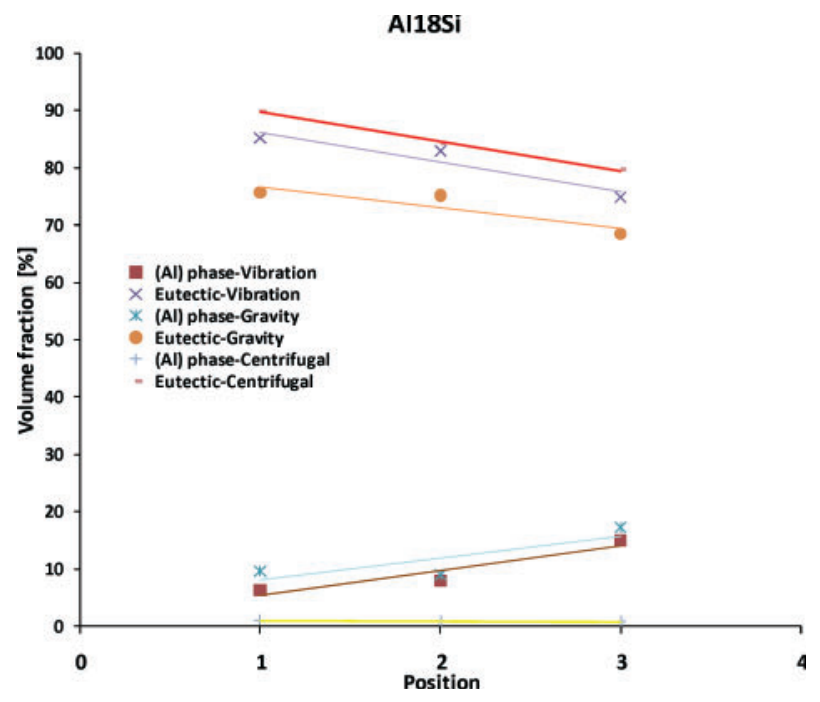

8 Phases quantification for three casting techniques: gravity; gravity with vibration $(8 \mathrm{~Hz})$; centrifugal casting

three positions. The opposite occurs for the $\alpha$-Al phase volume fraction.

Concerning the silicon lamellas their thickness increase from the outside regions of the samples (position 1) to the inside of them (position 3) in all casting techniques, following the decrease in the cooling rate. Comparing the effect of the casting technique on the same parameter, it was found that the eutectic thickness of the lamellas decreases from gravity (thicker) to centrifugal casting (thinner).

\section{Discussion}

From the literature review, it could be stated that the centrifugal effect on the mechanical properties and microstructure of cast samples is not yet very well understood by the scientific community. ${ }^{2}$ In order to better understand the centrifugal effect on castings this study focused its analysis in three main features: centrifugal pressure, intrinsic vibration of the process and fluid dynamics. The effect on mechanical properties of each of these variables will be subsequently discussed.

\section{Centrifugal pressure}

The centrifugal pressure exerted over a certain region of a centrifugally cast sample during rotation depends on some variables namely the angular speed, the distance from the mould cavity to the rotation axis, the quantity of poured material, the geometry of the sample and its position in the mould. For the specific case used in this study the pressure level is about 2 to $4 \mathrm{MPa}$. It is known that in squeeze casting pressure significantly improves the mechanical properties of the castings. ${ }^{17}$ This improvement is attributed to the shift of the solidification diagram and to the reduction on microporosities. However, in order to promote a shift in the solidification diagram a high pressure level would be needed, as it happens in squeeze casting where pressures may reach 50-200 MPa. In centrifugal casting the pressure is much lower when compared with the pressures used on squeeze casting (more then an order of magnitude lower), so it is expected and assumed that the low pressures on the centrifugal casting technique are not able to shift the solidification diagram. On a previous

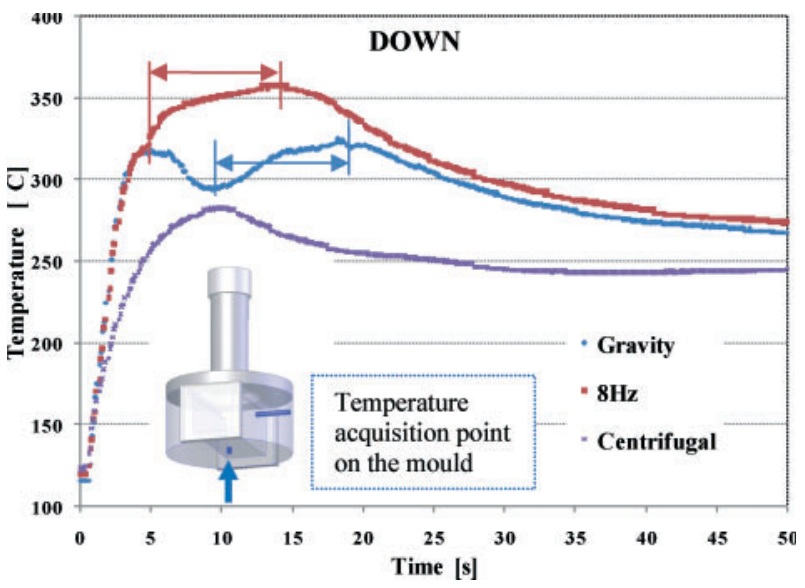

9 Experimental solidification curves for studied casting techniques at bottom of mould

study, ${ }^{13}$ it was observed that the microporosity level did not change significantly due to centrifugal pressure for the materials used in this study. It was also observed that in these alloys pressure does not promote a displacement of more dense solid phases along the direction of the centrifugal force. ${ }^{13}$ Thus, if the centrifugal pressure does not seem to have any effect on mechanical and metallurgical properties, it must have been the melt fluid dynamics and the inherent vibration of the system those factors responsible for registered substantial changes.

\section{Vibration}

The vibration effect was assessed by introducing a linear vibrating movement, similar to the one measured on the centrifugal casting machine, on gravity casting. It was observed that it has a beneficial effect (Figs. 5 and 6) on mechanical properties (an increase of about $20 \%$ on rupture strength and about $40 \%$ on rupture strain), when compared to gravity casting. It was also observed that the vibration effect also influences the microstructure (Fig. 7) increasing the eutectic silicon volume fraction and reducing the eutectic lamellas thickness. These effects are those that would be expected from a higher solidification rate. ${ }^{19}$

As a fact, it can be seen from the solidification curves shown in Fig. 9 and the results presented in Table 1 that a difference exists on the solidification behaviour between castings with and without vibration.

In gravity casting with vibration the solidification starts first and the solidification interval is shorter (Fig. 9 and Table 1) if compared with simple gravity casting. This difference in the solidification pattern seems to be the responsible for the reduction of the silicon lamellas thickness (Fig. 10) and the increase in the eutectic volume fraction (Fig. 8). The mechanism that promotes the faster solidification behaviour due to vibration is that there exists an internal movement of the melt that promotes a quicker heat transfer inside the

Table 1 Solidification time: starting and interval (down position)

Gravity Gravity with vibration

Starting solidification point, s $9.6 \quad 5.0$

Solidification interval, s $\quad 9.5 \quad 9.0$ 


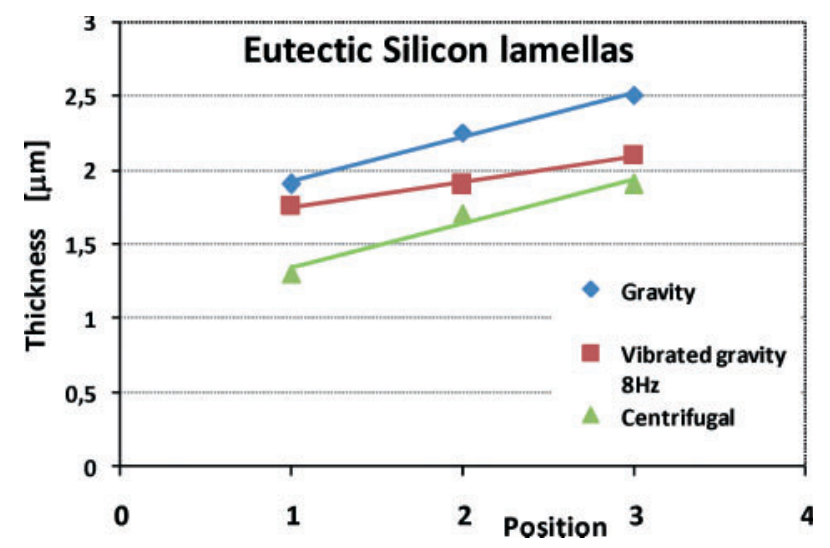

10 Thickness silicon lamellas of for three casting techniques: gravity; gravity with vibration $(8 \mathrm{~Hz})$; centrifugal casting

melt and to the mould, probably as a result of the elimination of the usually existing gap at the metal/ mould interface, thus improving the metal-mould contact and the heat transfer rate. This vibration effect may also be attributed to a faster distribution of solidification germens inside the melt due to internal melt movement.

In general, the vibration effect is in accordance with most of the existing studies ${ }^{6,20-22}$ which state that it improves the mechanical properties of the materials. However, a deeper study on the influence of the vibration effect under different acceleration values is provided in ref. 25 . In that study the mechanisms under which external vibration promotes higher or lower mechanical properties and the related mechanisms are presented.

\section{Fluid dynamics}

The fluid dynamics may be very different between gravity castings and centrifugal castings

The experimental solidification curves at the bottom of the casting/mould (Fig. 9) show that for the three casting techniques used on this research, the gravity and vibrating gravity castings present an expected shape with starting and ending solidification points well defined. However, in the centrifugal solidification curve those points are not clearly defined. This is probably due to the constant liquid movement (see fluid dynamics simulation shown in Fig. 11) that does not allow a

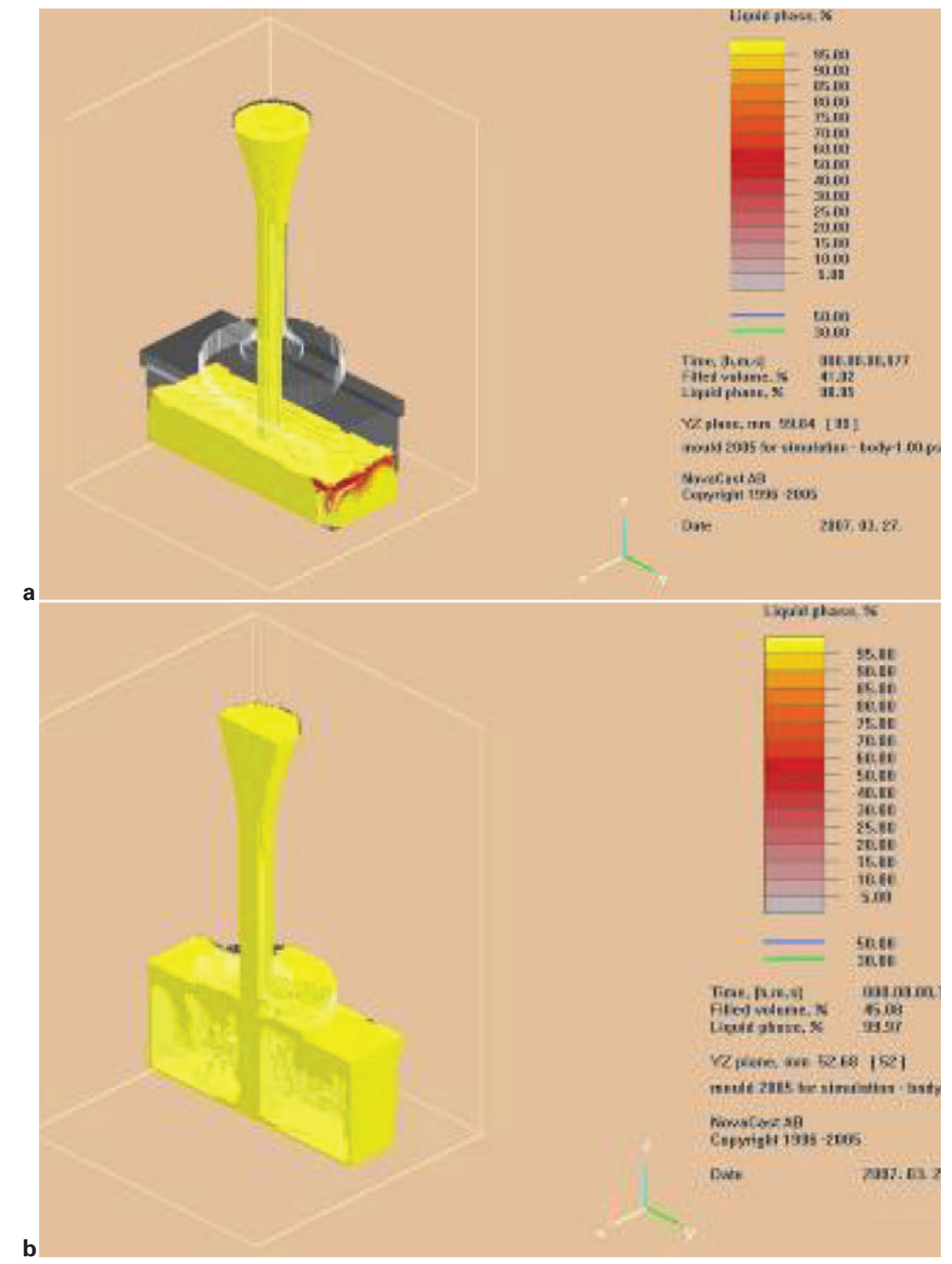

11 Detail of filling of molten material on a gravity casting (time: $0.997 \mathrm{~s}$ ) and $b$ casting with pressure (time: $0.192 \mathrm{~s}$ ) 


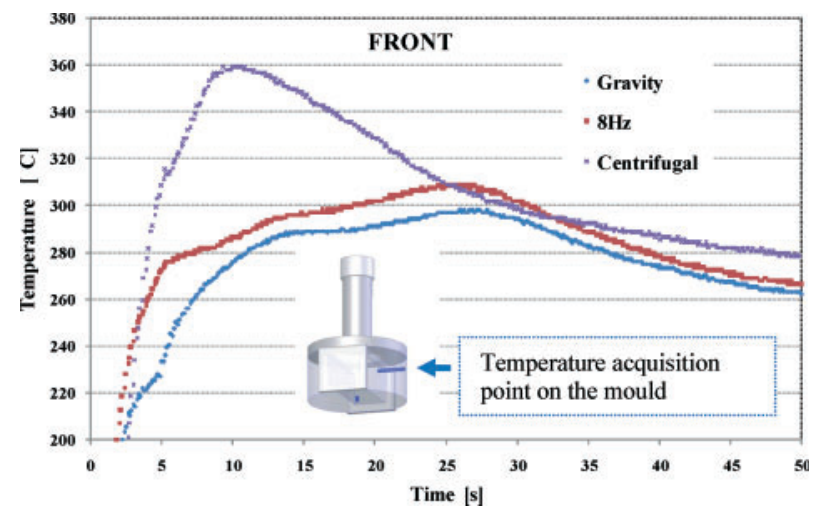

12 Solidification curves for studied casting techniques at front of mould

directional solidification from the mould wall to the inner part of the casting as it happens in the other casting techniques (gravity and vibrating gravity casting). On the other hand, the maximum attained temperature is lower than in the other curves because the first liquid to touch the bottom (hot metal) is spread very fast along the whole mould dispersing the heat transfer to the whole mould, instead of concentrating on the bottom as it happens in gravity and vibrating gravity casting. This is why the maximum temperature at the front part of the mould is now higher for centrifugal casting then for gravity and gravity with vibration casting (see Fig. 12). This is also explained by the simulation in Fig. 11. While the gravity casting fills the mould from bottom to top in the pressure casting the metal is spread by the whole mould and it is filled from the walls to the inside of casting.

In the same simulation, it is also observed that pressure casting promotes a quicker and a more turbulent mould filling (Fig. 13). In pressure casting the mould is filled in less then $0.4 \mathrm{~s}$ and takes about $2 \mathrm{~s}$ to fill in gravity atmospheric castings. Turbulence will be the responsible for the more uniform distribution of the solidification germens (that arise from first contact with the mould walls) and consequently will create a different solidification pattern and faster solidification rate of the casting.

This is in accordance with ref. 23 where it is stated that in centrifugal castings the first melt that reaches the wall surface (bottom) of the mould (where the first germens of solidification appear) will came backwards to the side parts of the casting creating a fluid dynamics flow all around the casting.

Furthermore, in the present work, the faster solidification rate will lead to a thinner microstructure (silicon lamellas), higher eutectic volume fraction, and consequently better mechanical properties. The difference between centrifugal and gravity casting techniques in what concerns to rupture strength and rupture strain is about 20 and $500 \%$ respectively.

It is worth to note that the results of centrifugal casting include the effect of the inherent vibration of the mould. Thus, as schematically shown in Fig. 14, the centrifugal effect on mechanical properties (tensile strength and strain) can be understood as a sum of the vibration effect and the fluid dynamics effect. Starting from the gravity castings properties (blue line), the properties increase to the green line if the vibration effect is added, and increase again to the red line if the fluid dynamics is also added.

\section{Conclusions}

The main conclusions of this work can be drawn.

1. Centrifugal casting significantly increases the mechanical properties of the castings.

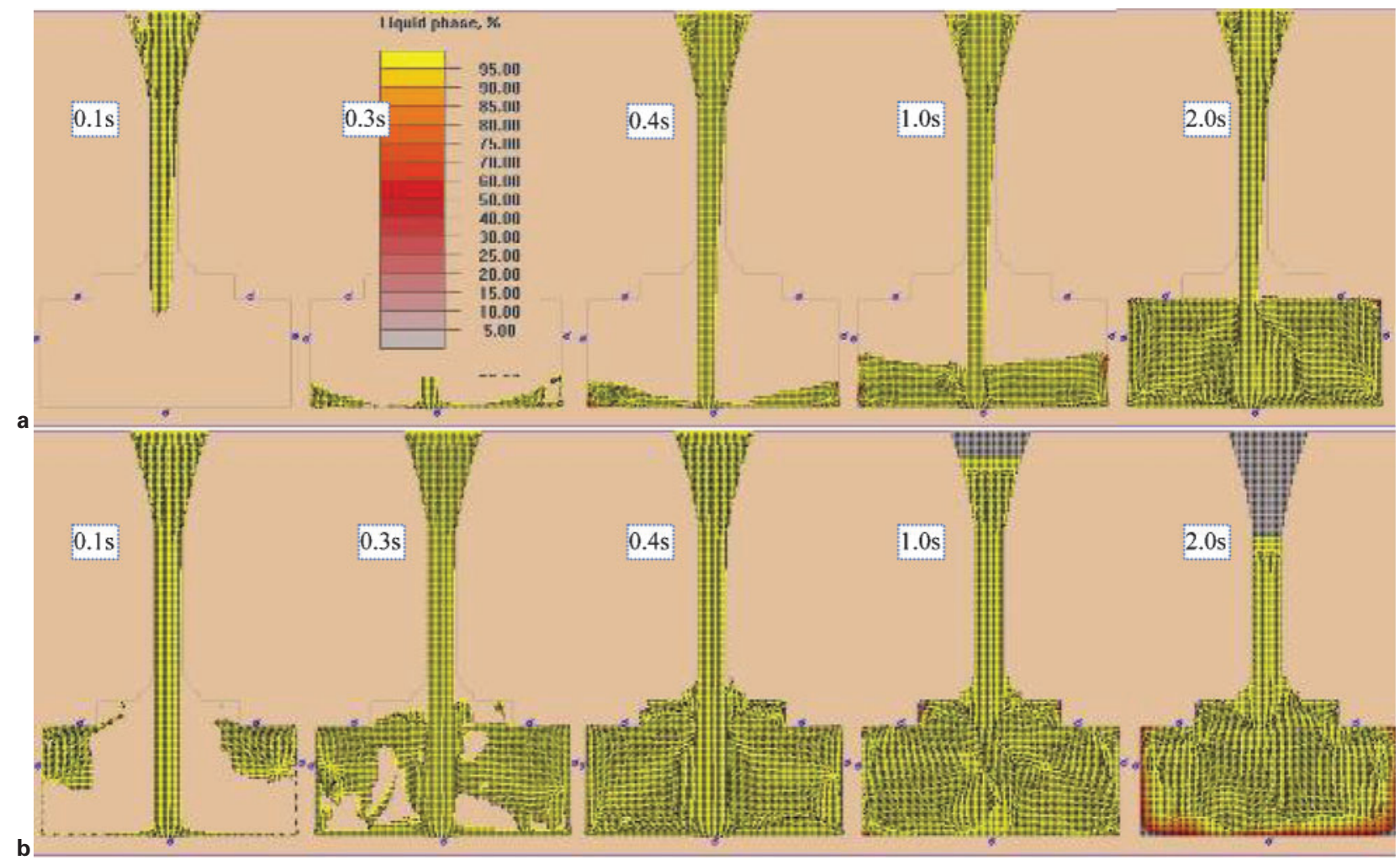

13 Simulation of fluid dynamics sequence during filling of mould on a gravity casting and $b$ casting with pressure 


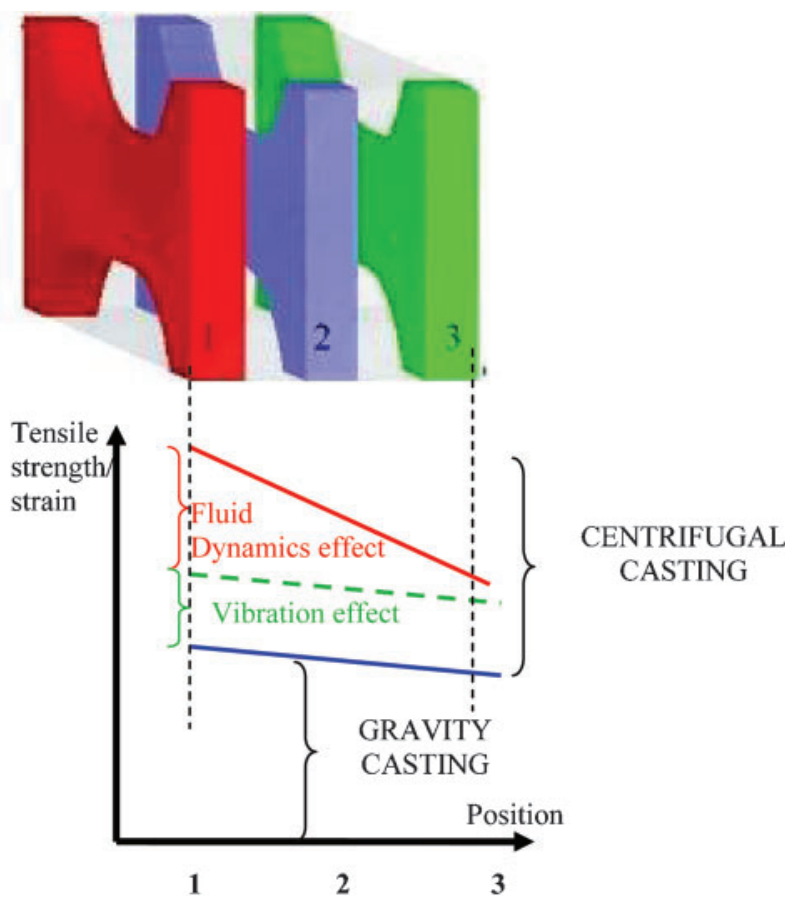

14 Schematical representation of main centrifugal effects

2. The centrifugal pressure does not seem to substantially influence the casting properties.

3. The inherent vibration of the centrifugal casting has a significant influence on casting mechanical properties, by promoting a quicker solidification rate.

4. The fluid dynamics effect of the centrifugal casting is the main factor promoting higher mechanical properties by dispersing the mould temperature transfer through the whole mould thus increasing the solidification rate.

5. The vertical centrifugal casting effect can then be understood as a sum of both the inherent vibration and the fluid dynamics effects.

\section{Acknowledgements}

The research presented was carried out in Materials Testing Laboratory of the Mechanical Engineering Department of University of Minho, and was supported by 'Fundação para a Ciência e Tecnologia' (Portugal) through the $\mathrm{PhD}$ grant with the reference SFRH/BD/ $19618 / 2004$.

\section{References}

1. 'Metal handbook', 9th edn, Vol. 15, 'Casting', 296-307; 1997, Materials Park, $\mathrm{OH}, \mathrm{ASM}$ international.

2. N. Janco: 'Centrifugal casting'; 1998, American Foundrymen Society, Inc.

3. M. M. Haque and M. A. Maleque: J. Mater. Process. Technol., $1998,77,122-128$

4. M. M. Haque and A. Sharif: J. Mater. Process. Technol., 2001, 118, 69-73.

5. Q. G. Wang: Metall. Mater. Trans. A, 2003, 34A, 2887-2899.

6. A. J. Moffat, S. Barnes, B. G. Mellor and P. A. S. Reed: Int. J. Fatigue, 2005, 27, 1564-1570.

7. X. Jian, T. T. Meek and Q. Han: Scr. Mater., 2006, 54, 893-896.

8. N. Abu-Dheir, M. Khraisheh, K. Saito and A. Male: Mater. Sci. Eng. A, 2005, A393, 109-117.

9. J. Asensio-Lozano and B. Suarez-Pena: Scr. Mater., 2006, 54, $943-$ 947.

10. Y. C. Lee, A. K. Dahle, D. H. StJohn and J. E. C. Hutt: Mater. Sci. Eng. A, 1999, A259, 43-52.

11. L. Y. Pio, S. Sulaiman, A. M. Hamouda and M. M. H. Megat Ahmad: J. Mater. Process. Technol., 2005, 162-163, 435441 .

12. P. S. Mohanty and J. E. Gruzleski: Acta Mater., 1996, 44, (9), 3749-3760.

13. G. Chirita, D. Soares and F. S. Silva: Mater. Des., 2008, 29, (1), 20 27.

14. M. T. Abou El-khair: Mater. Lett., 2005, 59, 894-900.

15. A. Halvaee and A. Talebi: J. Mater. Process. Technol., 2001, 118, $123-127$.

16. A. Maleki, B. Niroumand and A. Shafyei: Mater. Sci. Eng. A, 2006, A428, 135-140.

17. M. R. Ghomashch and A. Vikhrov: J. Mater. Process. Technol., 2001, 101, 1-9.

18. J. K. Kim and P. K. Rohatgi: Mater. Sci. Eng. A, 1998, A244, 168177.

19. G. Chirita, I. Stefanescu, D. Cruz, D. Soares and F. S. Silva: Submitted to J. Eng. Mater. Technol.

20. T. P. Fisher: Br. Foundryman, 1973, 66, (3), 71-83

21. A. A. Ivanov and G. G. Krushenka: Liteinoe Proizvod, 1993, (3), 78.

22. K. Kocatepe: Mater. Des., 2007, 28, (6), 1767-1775.

23. S. R. Chang, J. M. Kim and C. P. Hong: ISIJ Int., 2001, 41, (7), 738-747.

24. J. K. Kim and P. K. Rohatgi: Mater. Sci. Eng. A, 1998, A244, 168177.

25. G. Chirita, I. Stefanescu, D. Soares and F. S. Silva: Mater. Des., 2008 , to be published. 